\title{
An analysis of the efficiency of a Rhesus haemolytic disease prophylaxis programme
}

\author{
P. M. CROWLE \\ Department of Paediatrics, Birmingham Maternity Hospital
}

\begin{abstract}
SUMMARY
A method of implementing the anti-D prophylaxis programme is described and its efficiency is studied by examination of the records of 889 Rhesus-negative mothers. During one calendar year only eight $(0.9 \%)$ cases were found where there was failure to follow the correct procedure and to administer anti-D. Sixty-two point five per cent of the mothers who were given anti-D received it within 24 hours and all but 3\% within 48 hours. Methods of improving the programme are discussed.
\end{abstract}

\section{INTRODUCTION}

The original suggestion that injection of passive anti-D might prevent Rhesus immunization (Finn, 1960 ) has been amply justified in practice (Clarke et al., 1966; Freda, Gorman, and Pollack, 1966; Chown et al., 1969). Anti-D must be given in a dose appropriate to the volume of fetomaternal transfusion of Rhesus-positive blood, and also within 24 hours. An apparent failure of anti-D prophylaxis may be seen following fetomaternal haemorrhage at therapeutic or spontaneous abortion (Bowman, 1970a), and it is now the policy to give Rhesusnegative women anti-D at the time of such abortions. True failure of anti-D to protect from immunization does occur. Using the data collected by Clarke (1970), $13(1 \cdot 1 \%)$ of 1,139 women were immunized, despite receiving anti-D at the end of the second pregnancy. The reason for this could be either an exceptionally large transplacental haemorrhage, or that the mother has been primed by the baby but that antibodies are not yet detectable at the time of delivery.

The chief remaining reasons for a woman to develop Rhesus $D$ antibodies are now failure to identify a patient at risk and/or failure to give anti-D. This aspect of 'failure' has received little attention, but Bowman (1970b) found that $13 \%$ of urban and $73 \%$ of rural women at risk failed to receive anti-D, giving an estimated overall failure rate in Manitoba of around $25 \%$.
It was therefore decided to evaluate the efficiency of the anti-D programme in this hospital, which handles a quarter of the deliveries in a city where over $90 \%$ of the total births occur in hospital.

\section{Materials AND Methods}

All women attending the Birmingham Maternity Hospital for booking for the first time have blood tested for group and the presence of antibodies, and the results are written in a prominent place on the first page of the clinical notes. When a woman is admitted in labour, the blood group is one of the items of information extracted from the notes and put in the midwives' nursing records. The importance of ensuring that the whole delivery team knows the patient's blood group has been repeatedly emphasized as this first step is essential for the subsequent smooth running of the programme.

At the time of delivery, cord blood is obtained and a maternal venous specimen is taken from all Rhesus-negative women as soon after delivery as is practicable, normally about 20 minutes afterwards. The specimens and a request card are sent to the laboratory. Should cord blood not be obtained, the card and the maternal blood are still sent to the laboratory, but capillary blood is subsequently obtained by the haematology staff from the baby. In the case of non-booked emergencies, maternal blood is withdrawn on admission for blood grouping in all cases and the above procedure is followed if the mother is Rhesus-negative. In stillbirths, where it is not possible to obtain fetal blood, anti-D is given in the dose described below.

Tests on the blood samples are performed each day (including public holidays) except Sunday, and the baby's blood group is established and a Coombs' test done. If the baby is Rhesus-negative, no further action is taken. If the baby is Rhesus-positive, the maternal blood is subjected to Shepherd's modification of the Kleihauer test. Should less than two fetal cells be seen in each low-power field on scanning, then $100 \mu \mathrm{g}$ of anti-D are given to the mother. 
If more than two cells are seen, a larger fetomaternal haemorrhage is assumed and an accurate count of fetal cells in $\mathbf{5 0}$ low-powered fields is made according to the method of Woodrow and Donohoe (1968). In larger haemorrhages the amount of anti-D is increased in proportion to the volume of bleeding.

When anti-D therapy is indicated, the appropriate number of vials of anti-D, together with a special form, are sent to the ward. This form, which is in triplicate, shows the blood group of the mother and baby, the time and date of both the delivery and injection of anti-D, as well as identification details. Of three copies, one is retained in the patient's notes, one is sent to the general practitioner, and one is sent to the Regional Blood Transfusion Service.

In this survey the records computer produced a list of 742 Rhesus-negative women who were delivered in 1972. A further 147 names were obtained from the haematology records, making a total of 889. This represents $17 \cdot 6 \%$ of the 5,054 deliveries in this hospital in 1972, and compares well with the national figure of $17 \%$ (Race and Sanger, 1962) for Rhesus D negative people in the general population. In each case the patient's notes were examined to ensure that

(1) the woman was Rhesus negative,

(2) the appropriate maternal and infant samples were obtained,

(3) the samples received the correct investigatory procedures,

(4) anti-D was given when appropriate,

(5) anti-D was administered within 72 hours.

\section{RESULTS}

Table I shows the total number of women receiving, or not receiving, anti-D and lists the reasons when no anti-D was given. The postpartum sterilizations were usually performed six weeks after delivery.

TABle I

RESULTS OF TREATMENT OF WOMEN INVOLVED IN ANTI-D PROGRAMME

\begin{tabular}{llll|r}
\hline \multicolumn{3}{c|}{ Treatment } & & No. \\
\hline $\begin{array}{l}\text { Received anti-D injection } \\
\text { Did not receive anti-D because: } \\
\text { already immunized }\end{array}$ & $\ldots$ & $\ldots$ & $\ldots$ & 456 \\
$\begin{array}{l}\text { Rhesus-negative baby } \\
\text { sterilized at Caesarean section } \\
\text { postpartum sterilization }\end{array}$ & $\ldots$ & $\ldots$ & $\ldots$ & 58 \\
$\begin{array}{l}\text { Rhesug-negative husband } \\
\text { refused anti-D (husband sterilized) } \\
\text { failure in anti-D programme }\end{array}$ & $\ldots$ & $\ldots$ & $\ldots$ & 350 \\
\hline Total .. & $\ldots$ & $\ldots$ & $\ldots$ & 5 \\
\hline
\end{tabular}

TABLE II

CLINICAL DETAILS OF WOMEN FAILING TO BE ADEQUATELY PROTECTED

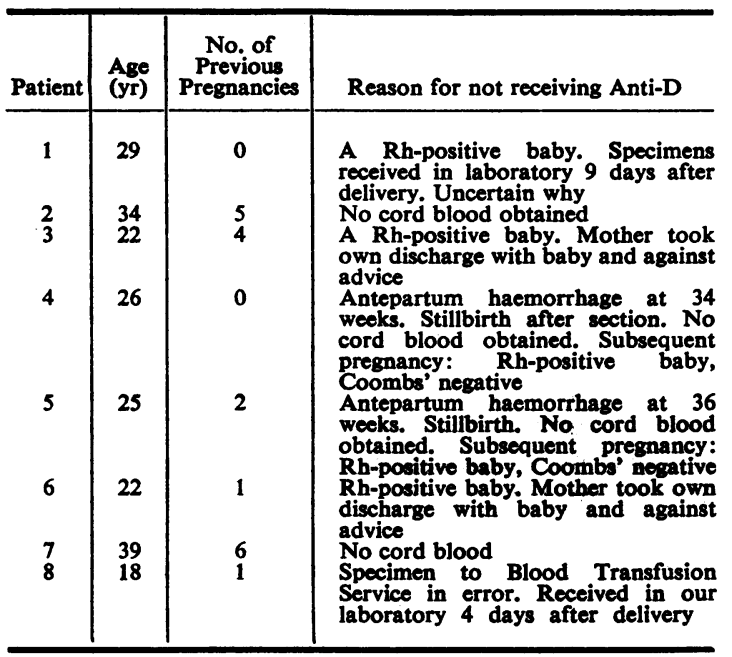

Table II gives the clinical details of the eight 'failures' in the implementation of the programme although it is possible that some of the babies mat have been Rhesus-negative or, even if positive have failed to cause immunization. The two mothers (cases 3 and 6) who took their own and their babies' discharge against medical advice could have received anti-D injections at home, given by a domiciliary midwife or general practitioner, if the problem had been identified early enough. In two cases (1 and 8) specimens were misdirected and failed to reach the appropriate laboratory in time, while in the remaining four cases there was failure to appreciate that the mother was Rhesus-negative and so obtain the appropriate specimens. These eight failures in implementing the anti-D programme represent $0.9 \%$ of the 889 Rhesus-negative mothers who were delivered in this hospital in one calendar year.

TABLE III

TIME INTERVAL BETWEEN DELIVERY AND INJECTION

\begin{tabular}{c|rr}
\hline Hours & No. & $\%$ \\
\hline $0-12$ & 54 & $12 \cdot 0$ \\
$13-24$ & 228 & 50.6 \\
$25-36$ & 89 & $19 \cdot 7$ \\
$37-48$ & 66 & 14.6 \\
$49-72$ & 14 & $3 \cdot 1$ \\
\hline & 451 & $100 \cdot 0$ \\
\hline
\end{tabular}

Table III shows the time between delivery and $\stackrel{0}{\Phi}$ injection in 451 out of 456 mothers where such $\frac{?}{\mathbb{D}}$ information was obtained or could be derived, $\varrho$ 
assuming the anti-D is given before 17.30 hours on the day it is issued. As can be seen, $62.5 \%$ of the mothers received the injection in the first 24 hours, and a further $34.5 \%$ in the second 24 hours. Only $3 \%$ were given anti-D in the third 24 hours.

\section{Discussion}

Woodrow and Donohoe (1968) have shown that only $8.5 \%$ of Rhesus-negative mothers have antibodies six months after delivery of a Rhesuspositive fetus. A further $8.5 \%$ develop antibodies during the second pregnancy, probably as a result of priming in the first, so it is not surprising that our motheis (patients 4 and 5) who failed to receive anti-D in this programme have not developed antibodies in their subsequent Rhesus-positive pregnancy. Nevertheless this good fortune does not alter the fact that failure occurred in an important aspect of preventive medicine.

In view of the possibility of changing her intention, a mother planning to have a postpartum sterilization at six weeks should probably receive anti-D, especially if the infant has difficulties in the first few hours of life. In these permissive days, and particularly in primiparae where paternity is often in doubt in infants conceived before marriage (Edwards, 1957), it might be inadvisable to assume that a Rhesus-negative husband is, in fact, the father.

Examination of the reasons for 'failure' in implementing the programme suggests various methods of presentation. Improved liaison between ward, haematology department, and general practitioner would permit women who leave hospital early and contrary to advice to receive anti-D at home. Clarity in the instructions given by senior staff to porters and ward clerks should prevent blood samples being lost (case 1) or sent to the wrong laboratory (case 8). In the latter case, confusion probably arose because cord blood of babies born to immunized mothers is routinely sent to the Blood Transfusion Service.

The results show that increased vigilance in identifying Rhesus-negative women in labour would produce most benefit (cases 2, 4, 5, and 6). Mothers of stillbirths are proportionately more at risk, probably because no cord blood is obtained, and the mother tends to be discharged home as soon as possible. When a patient in labour has blood crossmatched, the haematology staff may be able to ensure that correct samples are obtained from
Rhesus-negative women. Nevertheless, it is the admitting clinician who is primarily responsible for ensuring that the whole delivery team knows the Rhesus status of each mother in labour.

We should also consider other potential causes of immunization. With increasing use of diagnostic amniocentesis for the identification of genetic disease, it might be wise to give Rhesus-negative mothers anti-D at the time of the procedure in case the fetus is Rhesus-positive.

In conclusion, the anti-D programme described here should do much to lower the incidence of Rhesus haemolytic disease of the newborn, and the modifications suggested should improve matters further to the mutual benefit of clinicians and parents of the future.

I should like to thank Dr. J. Insley for helpful criticisms of the manuscript and Dr. J. Stuart, Miss A. Hudson, and Mr. A. Picken, of the Haematology Department, for their help in the preparation of this paper. The study forms part of a project financed by the Endowment Fund of the United Birmingham Hospitals.

\section{REFERENCES}

Bowman, J. M. (1970a). Transplacental haemorrhage after abortion. Lancet, 1, 1108.

- (1970b). Prevention of haemolytic disease of the newborn. Brit. J. Haemat., 19, 653.

Chown, B. et al. (1969). Prevention of primary Rh immunisation: first report of the Western Canadian trial, 1966-1968. Canad. med. Ass. J., 100, 1021.

Clarke, C. A. (1970). Prevention of rhesus isoimmunization. Clin. Genet., 1, 183.

-, Finn, R., Lehane, D., McConnell, R. B., ShePPARD, P. M., and Woodrow, J. C. (1966). Dose of anti-D gamma-globulin in prevention of Rh-haemolytic disease of the newborn. Brit. med. J., 1, 213.

EDwards, J. H. (1957). A critical examination of the reputed primary influence of $\mathrm{ABO}$ phenotype on fertility and sex ratio. Brit. J. prev. soc. Med., 11, 79.

FINN, R. (1960). Erythroblastosis. Lancet, 1, 526.

Freda, V. J., Gorman, J. G., and Pollack, W. (1966). $\mathrm{Rh}$ factor: prevention of isoimmunization and clinical trial on mothers. Science, 151, 828.

RACE, R. R. and SANGER, R. (1962). Blood Groups in Man, 4th ed., p. 142, table 32. Blackwell Scientific Publications, Oxford.

Woodrow, J. C. and Donohoe, W. T. A. (1968). Rhimmunization by pregnancy: results of a survey of their relevance to prophylactic therapy. Brit. med. J., 4, 139. 